www.jmscr.igmpublication.org

Impact Factor (SJIF): 6.379

Index Copernicus Value: 71.58

ISSN (e)-2347-176x ISSN (p) 2455-0450

crossrefDOI: https://dx.doi.org/10.18535/jmscr/v6i7.172

\title{
Study Report on Work Life Imbalance Impact on Job Satisfaction in Non Clinical Staff of Oncology Department of Tertiary Health Care Center, Delhi
}

\author{
Authors \\ Dr Sonal Gaur ${ }^{1 *}$, Dr J.Swaminathan ${ }^{2}$ \\ ${ }^{1}$ Master's in Hospital Management, Delhi Pharmaceutical Sciences and Research University, Delhi \\ ${ }^{2}$ Assistant Professor, Dept. of Pharmacology, Delhi Pharmaceutical Sciences and Research University, Delhi \\ *Corresponding Author

\section{Dr Sonal Gaur} \\ Delhi Pharmaceutical Sciences and Research University, Govt. of. N.C.T of Delhi \\ Sector- 3 M.B. Road, Pushp Vihar,New Delhi-110017, India \\ Email: drsonalmanagementexcel@gmail.com,drsonalhomeopath@gmail.com
}

\begin{abstract}
The care purpose of this study is to determine impact of work life imbalance on employee job satisfaction in non clinical staff at Oncology Department of Tertiary Health Care Center, Delhi. The data was collected according to the Factors involved which are work life balance and job satisfaction with respect to flexible working condition, suitable salary structure and long working hours. Study includes a sample of 12 Non clinical employees gathered through Non random sampling which has been provided the basis for analysis. Data is collected through self structured questionnaire and analyzed through MS EXCEL using Simple Mathematical Tools like Percentage and The correlation results shows that there is significant positive relationship exist between job satisfaction and work life imbalance of Non clinical staff of Oncology Department of Tertiary Health Care Center. A balance between work and non work aspects is essentially required for both employees and employers. The ability to achieve satisfaction in all spheres' of life increases the value of inter personal relationships and as result organization performance too.

Keywords: Job satisfaction, work life balance, non clinical staff, Management, Oncology.
\end{abstract}

\section{Introduction}

Job Satisfaction is the key to land-up and to get involved with any Job. Every employee needs to be treated respectfully and fairly equal. Job satisfaction is reflection of fair organizational treatment. Job satisfaction is also indicator of emotional well being. Managers should focus on employee's job satisfaction, as dissatisfied employee is likely to provide inferior services. Job is main source of income and important component of employee's life. Job takes away a major part of worker's daytime daily and sometimes required overwork for extended hours which can affect his lifestyle thus physical well being too, also job lead to one's social standing therefore Job Satisfaction is very important for employee's physical, social, emotional and financial well being. 
According to $\left(\mathrm{LOCKE}^{1}, 1976\right)$ job satisfaction is a self reported emotional positive state which is due to appraisal of one's job and from job experience. (SPECTER $^{2}$, 1997) said that Job satisfaction is a dependent attitudinal variable which determines the level of individual job liking, also always job performance have positive correlation with job satisfaction.

(MULLINS $^{3}$, 1999) uncover the factors that impact job satisfaction of employee, are following: -

1. Individual factors like personality, education, age, marital status, etc.

2. Social factors like group working, opportunity for interaction and informal organization, relation with co-workers.

3. Cultural factors like attitude, belief and value.

4. Organizational factors like nature and size, formal structure, employee relationship, personnel policies and procedures, technology and work organization, supervision and styles of leadership.

5. Environmental factors like social, technical, economic and governmental influences.

\section{Work Life Balance}

Work Life balance practices are organizational changes which are required to reduce work and family conflicts. These work life balance practices made employees effective both personally and professionally. The more an employee has control over his working conditions, the more he is able to balance work and family.

(IQAN LAZAR ${ }^{4}$, 2010) said that, a successful balancing between work and personal life, leads to increase in quality of personal life relationships and organizational performance.

(SUSI.S $\left.^{5}, 2010\right)$ said that work life balance drives for employee's satisfaction. Organizations felt the necessity of work life balance for increasing employee productivity and retention, decrease work life imbalance; reduce employee stress, better life balance and job satisfaction. Work life balance practices need to be flourished in organization culture. Strong and cooperative culture of organization create employee retention in the organization.
(FELICITY ASIEDU APPIAH ${ }^{6}, 2013$ ) states that in order to enhance employee performance at home and work, work life balance is a necessity. Work and non work responsibilities are Gender based different. Researches show that female requires more work life balance than male. Researches also show that work life balance enhances performance of individual and of overall organization.

(R.LOCKWOOD ${ }^{7}, 2003$ ) states that work life balance is managing work and personal responsibility. Senior Management has responsibility to support Work life balance Programmes in organization. For work life benefits in work environment it is important to have a corporate culture that encourage supports and accept employees as individuals and their priorities beyond workplace. Work life balance programmes increases employee's motivation and productive capacity.

\section{Job Satisfaction}

Job Satisfaction means employee's general attitude towards job. It is used to show how much an individual feels connected with his job and working environment. Many organizations develops training programme and benefit packages for creating and retention of loyal employees. Longer an employee works more he became valuable asset to that organization.

(Ms Chetna pandey $\left.{ }^{8}, 2012\right)$ states that In Organizational Behavior most important attitude is job satisfaction. Every organization tries to make efficient workforce to control the well being of the organization as a result of which employee extend additional efforts to their job performance. Total Organizational performance depends on efficient and effective performance of individual staff of the organization.

(M.D. Pushpakumari ${ }^{9}$, 2008) states that once worker is satisfied, than it drives him to perform the task with great efforts.

A satisfied individual worker and his efforts and commitments are necessary for the success of the organization.

$\left(\mathrm{Al}-Z_{0 u b i}{ }^{10}, 2012\right)$ states that staff agrees to the fact that salaries can increase the job satisfaction 
and as a result level of individual performance additionally raised. Job satisfaction additionally will increase worker motivation at work. However Researches additionally examined that pay will result job satisfaction once other job characteristics found positive. Worker satisfaction explains that the staff is happy and organization is efficiently fulfilling their need and desires. Worker satisfaction will facilitate, to create commitment of staff towards organizational goals.

(Bharati Deshpande ${ }^{11}$, 2012) Found that money edges, worker relations, work setting and role clarity are the factors that measure job satisfaction of staff at work. Worker satisfaction may be considered as a major factor for worker's motivation and goal attainment.

(Afshan-Naseem $^{12}$, 2011) found that satisfied staff shows wonderful performance which results in organizational success and improved financial condition. Worker satisfaction will increase the standard of service delivery. Worker satisfaction results in client satisfaction, as client service success eventually depends on the kind of community delivering service. Results of the study show that worker's satisfaction works as a key issue of organization success.

\section{Relationship between Work-life-balance and Job Satisfaction}

In several organizations human resource managers follow and practice work life balance to increase employee's loyalty toward the organization. Additionally several organizations have realized the necessity of continuously developing quality of work-life programs in organization.

(Sakthivel Rania ${ }^{13}$, 2011) Found that recognition connected with work and life balance that results in worker's satisfaction and therefore the effects of recognition for the worker's contribution, mirrored in their satisfaction. Work task and personal life are positively connected. Pay is said to be mediating issue of work and life balance that will lead to boost up in worker's satisfaction. Higher benefit progra ms results in worker satisfaction. These days human resource study shows strong relationship between worker satisfaction and financial progress of business. In result organization concentrate on developing policies and programs on work life problems. Workers feel additional satisfaction with their work and family, once they get the advantages of work life balance programs provided by their employers.

(Yutaka Ueda ${ }^{14}$, 2012) Conclude that work life balance programs have totally different effects for male and female staff. Male staff found happy with all the 3 measures like job, work and life balance program and employer in comparison female staff which has a big relationship solely with employer satisfaction. Work life balance programs have bigger effects on workers with upper financial gain as compared to lower financial gain.

(Dr. Bhatia ${ }^{15}$, 2015) Conclude that organizations perpetually provide importance to productivity and as result stress inflated. Stress impacted both personal and work life. Work life balance provides balanced relationship between personal and work life. Researches show that there's direct relationship between job satisfaction and increased productivity. Organizational non financial rewards typically have a lot of impact on job satisfaction than finance rewards.

(Namrata Mohite ${ }^{16}$, 2014) States that the hospital clinical staff Job dissatisfaction has adverse effect on employee in term of health and wellbeing and in turn on organization as in term of increase absenteeism and turnover which directly affect the quality of health care service delivery. In study she found out that among all other factors like utilization, achievement etc. are Independence and Compensation only these two were major Areas of average employee satisfaction. 
Conceptual Model of Work Life Balance and Job Satisfaction and Impact on Organizational Commitment

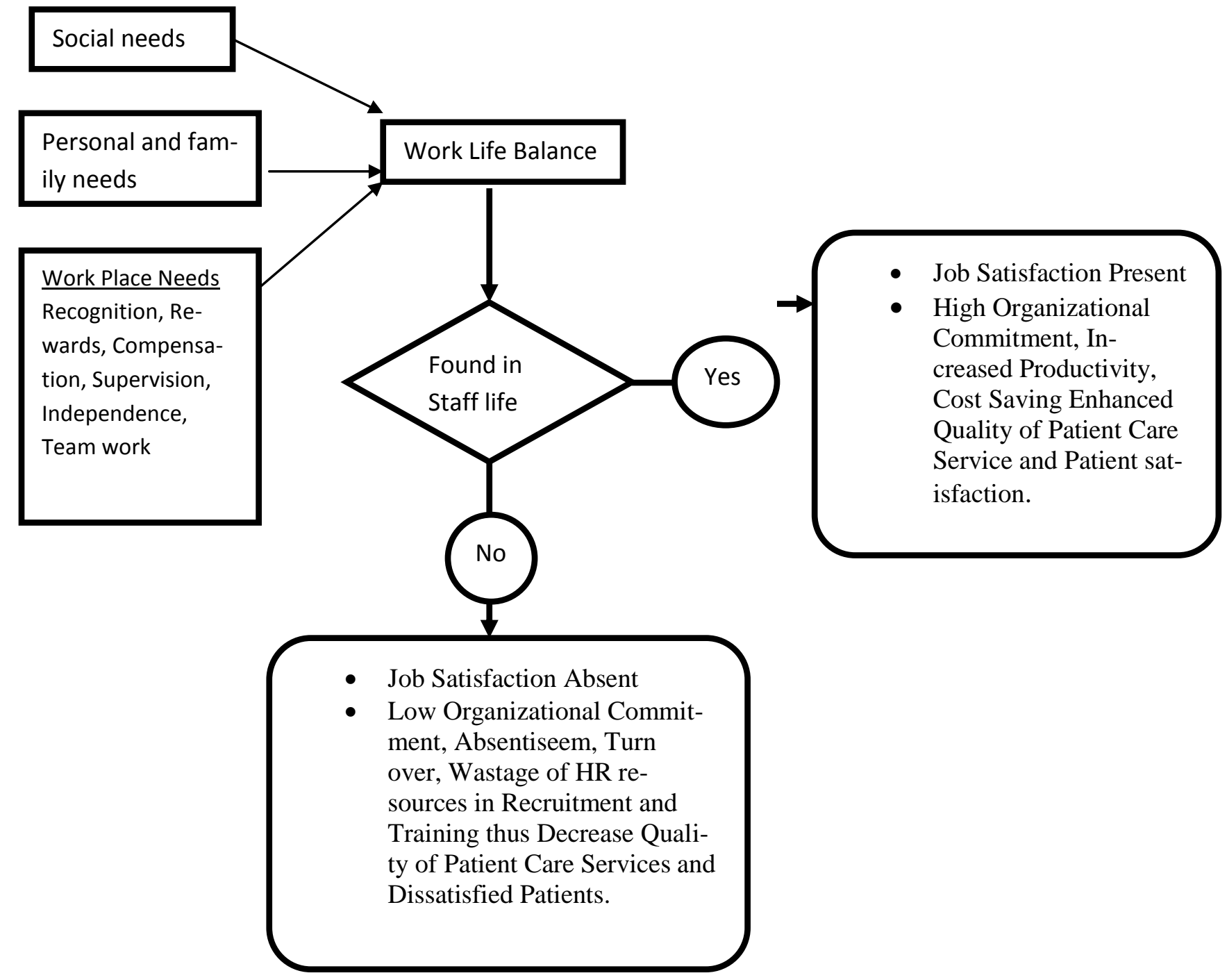

\section{Materials and Methods}

This co-relational and cross-sectional study conducted with the participation of the non clinical staff of the Oncology Department at tertiary healthcare center in Delhi in 2017.

Sample size consists of all the non clinical Staff working at Oncology Department at tertiary healthcare center in Delhi.

Inclusion criteria all the non clinical staff working in oncology department at tertiary health care center in Delhi, who gave Voluntary consent to participate in study.

Exclusion criteria only that staffs who does not give consent for the Study.
Data collection tool self structured questionnaire of 22 questions included the question based on job satisfaction, work life balance and work stress.

The questionnaire was based on 5 point Likert scale as

1 Extremely disagree

2 Somewhat disagree

3 Neutral

4 Somewhat agree

5 Extremely agree

All the questions described to participant in their understandable language (Hindi/English).

Data Analysis has done using MS Excel with the use of appropriate statistical tool like Percentage to analyze the relation between work life imbalance and job satisfaction of non clinical staff. 


\section{JMSCR Vol||06||Issue||07||Page 1040-1046||July}

\section{Results}

The following results show the correlation of work life balance on employee job satisfaction

\begin{tabular}{|l|c|}
\hline JOB SATISFACTION LEVEL & $\begin{array}{l}\text { JOB SATISFACTION PERCENT- } \\
\text { AGE IN NON CLINICAL STAFF }\end{array}$ \\
\hline Extremely satisfied & $27 \%$ \\
\hline Somewhat satisfied & $23 \%$ \\
\hline Neutral & $14 \%$ \\
\hline Somewhat dissatisfied & $17 \%$ \\
\hline Extremely Dissatisfied & $20 \%$ \\
\hline
\end{tabular}

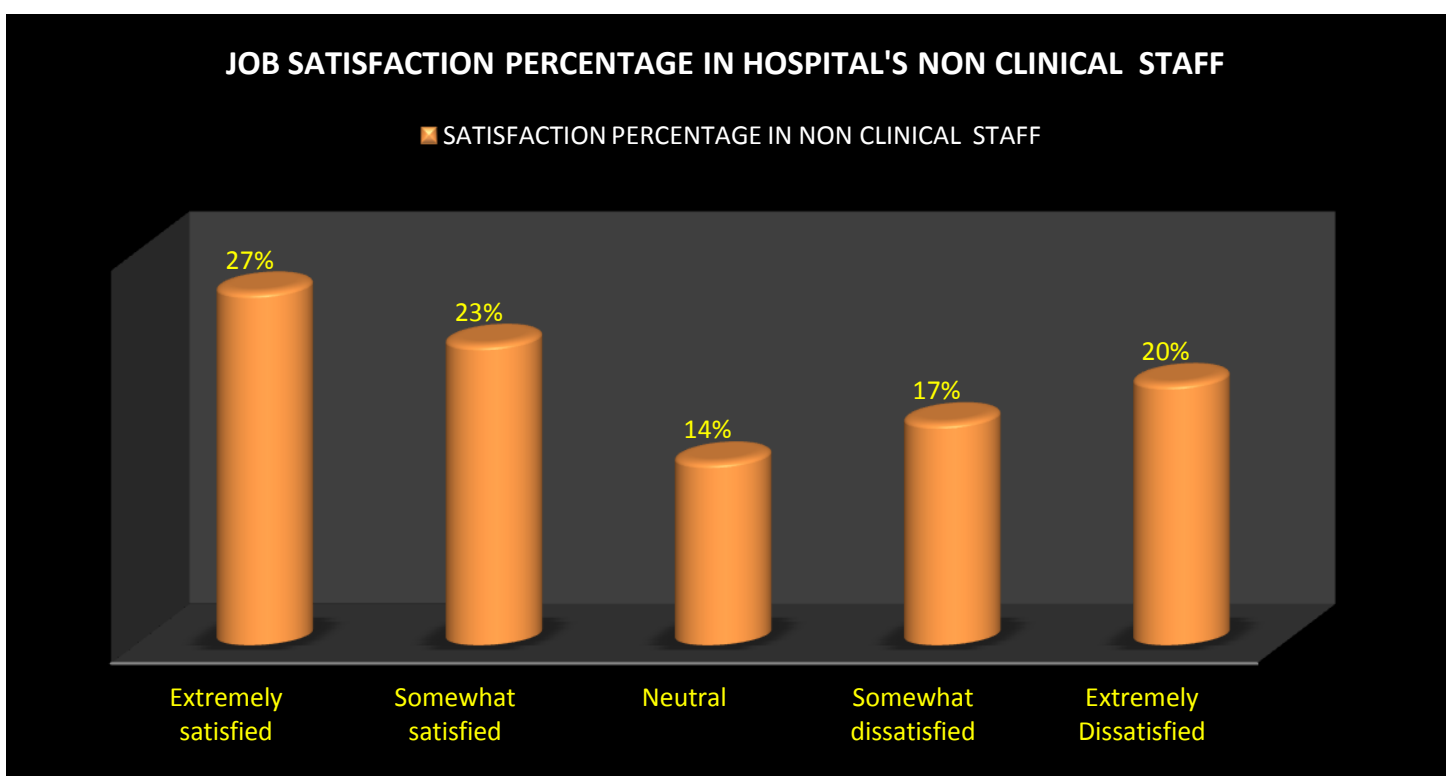

\section{Summarized finding}

\begin{tabular}{|l|c|}
\hline JOB SATISFACTION LEVEL & $\begin{array}{c}\text { JOB SATISFACTION PER- } \\
\text { CENTAGE IN HOSPITAL } \\
\text { NON CLINICAL STAFF }\end{array}$ \\
\hline SATISFIED(EXTREMELY+ SOMEWHAT) & $50 \%$ \\
\hline NEUTRAL & $14 \%$ \\
\hline DISSATISFIED(EXTREMELY+SOMEWHAT) & $37 \%$ \\
\hline
\end{tabular}

Job Satisfction Percentage in Hospital's Oncology Department Non Clinical Staff

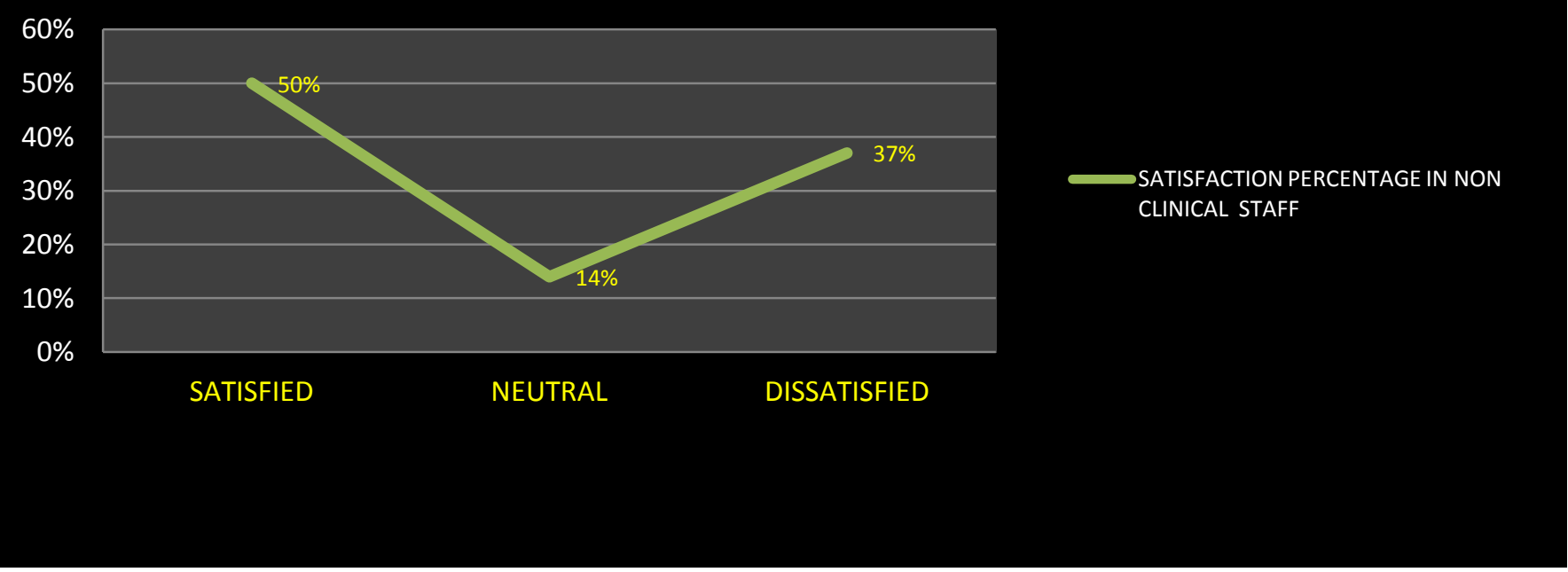




\begin{tabular}{|l|c|c|}
\hline \multicolumn{2}{|c|}{ Relation of Job satisfaction and work \& personal life satisfaction. } \\
\hline level of Satisfaction & $\begin{array}{c}\text { Percentage of work and Per- } \\
\text { sonal Life Satisfaction }\end{array}$ & $\begin{array}{c}\text { Percentage of Job } \\
\text { Satisfaction }\end{array}$ \\
\hline Satisfied & $60.00 \%$ & $50.00 \%$ \\
\hline Neutral & $10.00 \%$ & $14.00 \%$ \\
\hline Dissatisfied & $30 \%$ & $37.00 \%$ \\
\hline
\end{tabular}

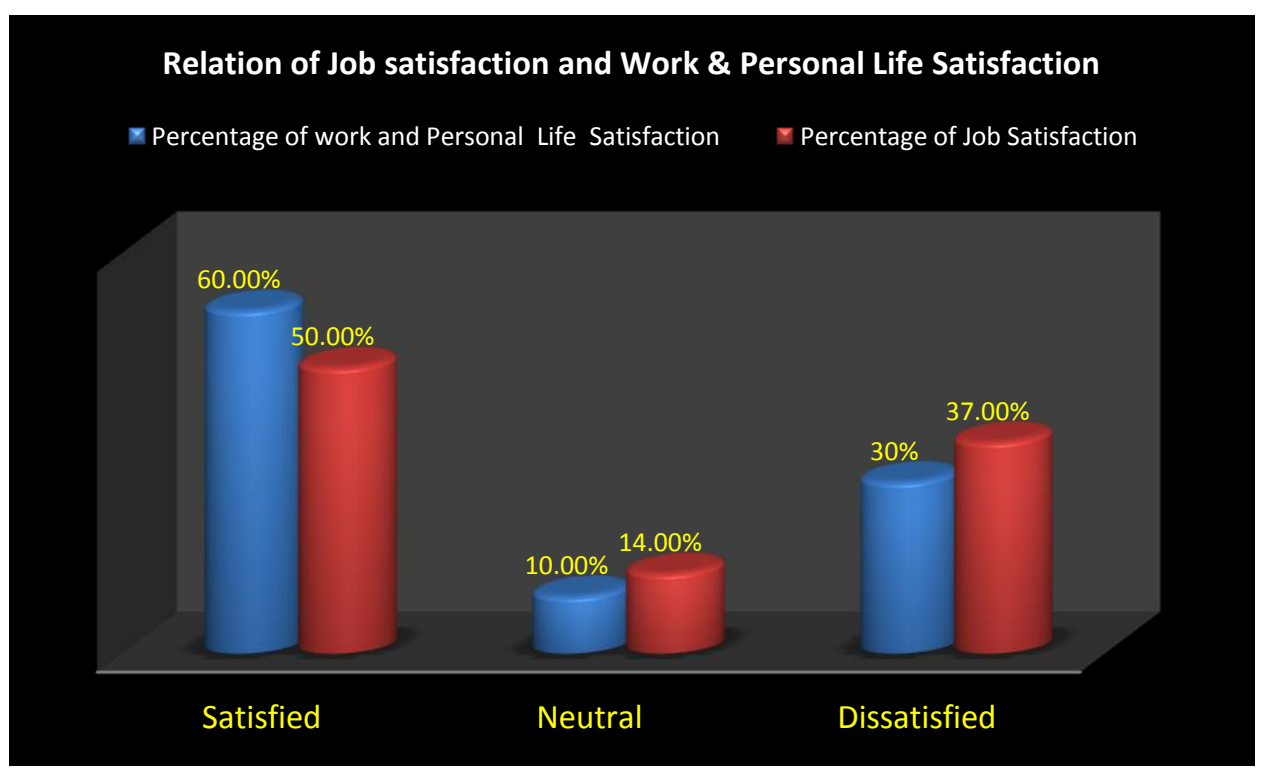

\section{Discussion}

According to this research Private and Work life balance have positive and strong relation with employee's Job satisfaction in Non Clinical Staff of Department of Oncology in Tertiary Health Care Institute.

Major areas of Satisfaction of employee's found are

1. Suitable working hours

2. Acceptable amount of work daily

3. Flexibility to complete work

4. Feel valued at work place

Major areas of Dissatisfaction of employee's found are

1. Perks/ incentives other than salary

2. Remuneration for my extra work/overtime

3. Compensation as per work

4. Takeout time for exercise and take care of their Health

\section{Conclusion}

This study shows a Positive correlation between the work \& personal life and Job satisfaction of employee.
Studies were found to represent that the more workers feel they have control over their working environment; the more they are able to balance work and family, which this Study also Contribute too. Conclusion of overall analysis is that work-life balance in organization can be achieve only after enhance employees' autonomy and increase their capability to perform well in work and in family scenario.

Availability and use of work-life balance practices, once provided by Management and their further support will cut back work-life conflict and organizations productivity will increase.

Remunerations and Compensations as per work along with additional monetary benefits play an important role in enhancing employee's job satisfaction level. Thus organizations need to be more concerned and sensitive about these factors.

A lower turnover intentions means: lower recruitment and training costs, increased retention of valuable employees and increased organizational commitment and loyalty.

All of these aspects are associated in hospital as these, in turn, provide more quality healthcare 
services with costs savings approach (employee retention and full utilization of man power potential), higher patient satisfaction and implicitly higher levels of organizational performance.

Thus increase in brand value of healthcare institution in society.

\section{Acknowledgement}

This study is a part of Master Hospital Management Observership thesis of Dr. Sonal and was supported by Department of Hospital Management, Delhi Pharmaceutical Sciences and Research University.

\section{Conflict of Interest}

The authors declared no conflicts of interest.

Funding: There was no funding or budget for this study, by any company or organization.

\section{References}

1. Locke, E. A. (1976). The nature and causes of Job Satisfaction. In M.D. Dunnette (Ed.), Handbook of Industrial and Organizational Psychology

2. Spector, P.E. (1997). Job satisfaction: Application, assessment, causes and consequences, SAGE, London.

3. Mullins L. (1999). Management and Organizational Behavior. 5th Ed. London: Person Education.

4. Iqan lazar, C. O. (2010). The role of work life balance practices in order to improve organizational performance. European Research Studies.

5. Susi. S, J. (2010). Work-Life Balance: The key driver of employee engagement. Asian journal of management research

6. Felicity Asiedu-Appiah, I. D.-M. (2013). Work-life balance as a tool for stress management in selected banking institutions in Ghana. Global advanced research journal of management and business studies.
7. R. Lockwood, N. (2003). Work life balance; challenges and solutions

8. Ms. Chetna pandey, M. k. (2012). Impact of job satisfaction and organizational commitment on employee loyalty. International journal of social science $\&$ interdisciplinary research

9. M.D. Pushpakumari. (2008). The impact of job satisfaction on job performance: An empirical analysis

10. Al-Zoubi, D. M. (2012). The shape of the relationship between salary and job satisfaction: A field study. Far East Journal of Psychology and Business,

11. Bharati Deshpande, K. A. (2012). Effect of employee satisfaction on organization performance: An empirical study in hotel industry. Ninth AIMS International conference on management.

12. Afshan Naseem, S. E. (2011). Impact of employee satisfaction on success of organizational: Relation between customer experience and employee satisfaction. International journal of multidisciplinary science and engineering

13. Sakthivel Rania, K. \&. (2011). Work- life balance reflections on employee satisfaction. Serbian journal of management

14. Yutaka Ueda. (2012). the relationship between work life balance programs and employee satisfaction: Gender differences in the moderating effect of annual income. Journal of Business Administration Research

15. Dr. Kanchan Bhatia, Work life balance: A key drive for job satisfaction, International Conference on Management Finance Economics

16. Namrata Mohite, Job Satisfaction among Nurses Working at Selected Tertiary Care Hospitals, International Journal of Science and Research. 